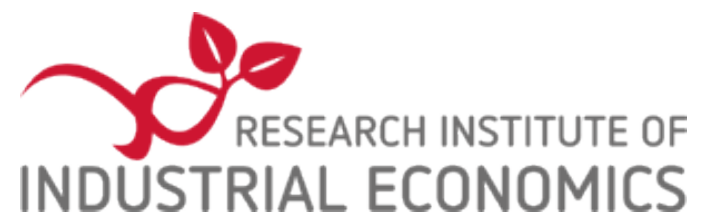

IFN Working Paper No. 1139, 2016

\title{
Effects of Privatization on Price and Labor Efficiency: The Swedish Electricity Distribution Sector
}

\author{
Erik Lundin
}




\title{
Effects of Privatization on Price and Labor Efficiency: The Swedish Electricity Distribution Sector
}

\author{
Erik Lundin*
}

\author{
November 1, 2016. \\ Link to the latest version
}

\begin{abstract}
I examine the effects of privatization, in the form of acquisitions, in the Swedish electricity distribution sector. As the majority of the distribution networks remained publicly owned, I use a synthetic control method to identify the effects on price and labor efficiency. In comparison to their synthetic counterparts, I find that the acquired networks increased labor efficiency by on average 18 percent, while no effect is found on the price. Thus, the evidence suggests substantial efficiency gains but that these are not fed through to consumer prices. Since each acquisition involved several bordering networks that were separately operated by each municipality prior to the acquisitions, I examine to what extent the efficiency gains are likely to be driven by increased economies of scale. Results suggest that the entire effect can be explained by increased economies of scale, questioning the causal effect of privatization per se.
\end{abstract}

JEL-Classification: L33, L52, L94

Keywords: Incentive regulation, electricity distribution, natural monopoly, norm model regulation, privatization, acquisitions.

*Research Institute of Industrial Economics. Email: erik.lundin@ifn.se. Website: www.eriklundin.org. The author would like to thank Pär Holmberg, Richard Friberg, and Thomas Tangerås for valuable comments. Financial support by the Swedish Energy Agency; the Swedish Competition Authority; and the Jan Wallander and Tom Hedelius Foundation is greatly appreciated. 


\section{Introduction}

When a network industry is privatized, a fundamental controversy lies in the potential increase in productive efficiency due to increased incentives to minimize costs, vs. distortions in allocative efficiency and a subsequent redistribution from consumers to producers due to market power. The electricity distribution sector is particularly well suited for firm performance comparisons since electricity distribution is a homogenous good, and since data on the technical characteristics of the networks as well as accounting data is standardized and reported to a central regulator. At the same time, since the market is regulated, the possibility to extrapolate results to other markets requires care.

In this study, I examine the effects of private acquisitions of publicly owned networks in the Swedish electricity distribution sector. Specifically, I compare the performance of 34 networks that were acquired by private firms around the turn of century, to 105 networks that remained publicly owned. I focus on two outcome variables: price and labor efficiency. I find evidence of an increase in labor efficiency in the acquired networks by on average 18 percent, while no acquisition effect is found on the price. Thus, the evidence suggests substantial efficiency gains but that these are not fed through to consumer prices. All acquisitions examined in the study were conducted by two firms, E.ON and Fortum. The qualitative effects on both outcome variables are similar across firms, although the increase in labor efficiency is both statistically and economically more significant in the networks acquired by Fortum.

To the best of my knowledge, this is the first study to use a synthetic control method to evaluate firm performance in the electricity distribution sector. For each acquired network, I create a synthetic control network from a weighted average of the networks that remained publicly owned. The synthetic control network is constructed to have identical, or close to identical, technical characteristics and pre-acquisition trend of the outcome variable as the acquired network. The effect of the acquisition is then estimated by comparing the factual post-acquisition trend of the outcome variable to that of its synthetic analogue. The method is particularly well suited to estimate the effect of an intervention when the number of potential control firms are large, and should therefore be useful also when estimating the effect of network specific interventions in the electricity 
distribution sectors in other countries. Also, results are invariant to the choice of cost function, since the observed cost determinants of the acquired network are identical to the cost determinants of its synthetic analogue.

In the synthetic control framework, the counterfactual is that the networks would have continued to be publicly owned by the same organizations as before the acquisitions. However, prior to the acquisitions, the networks were operated separately by the respective municipality in which they were located. Since each of the private firms conducted acquisitions of networks in several bordering municipalities, I also examine if the efficiency gains are likely to be driven by increased economies of scale, since the acquirers could centralize the management of the networks. Using a difference-in-differences (DID) estimator, results suggest that the entire efficiency effect can be explained by increased economies of scale, questioning the causal effect of privatization. However, since the private networks became substantially larger than any of the municipality owned networks due to the acquisitions, the identification of this test relies on the possibility to extrapolate outside the data in the municipality owned networks. Therefore, this result should be interpreted with care.

The choice of the electricity distribution sector as a testing ground for studying privatization is not only motivated by the availability of data and the diversity of the ownership structure. Another important factor is the increased skepticism against private ownership in network industries that has developed during the last decade, which can be exemplified by the experiences in Sweden and Germany. Prior to electricity reform, distribution networks in Sweden and Germany were usually owned by the municipalities. In Sweden, the state-owned firm Vattenfall also owned a fair share of the networks, and continues to do so (NordReg, 2011; OECD, 2004). However, the last two decades have seen a transition towards consolidation and privatization of the network ownership structure. In Sweden, the new entrants Fortum and E.ON now have a market share of around 40 percent. Consumer groups claim that the sharp price increases during the last decade are mainly driven by the largest firms (SABO, 2011), and some municipalities have expressed an interest in buying back their networks (Dalarna's newspaper, 2014). Germany has seen a similar development, where the four largest firms acquired shares in numerous local distribution networks during the privatization wave initiated by the municipalities 
around the turn of the century. However, in contrast to Sweden, there has been a reverse trend in network ownership during recent years. Municipalities, often guided by the will of the local people, have started to repurchase the networks (the so-called Rekommunalisierung, or remunicipalization). The two most notable events were the referendums in the two largest German municipalities, Berlin and Hamburg, which in 2013 both voted for the remunicipalization of the electricity, gas, and district heating networks (although the referendum in Berlin failed due to insufficient voter turnout). Similar skepticism towards private ownership of network industries has also been raised elsewhere. For example, the website www.remunicipalisation.org collects data on remunicipalization projects of water provision services throughout the world, recording 235 cases during the last 15 years, impacting 100 million people. The recent years' remunicipalization trend further highlights the importance of examining the effects of privatization in network industries.

Previous studies on the relationship between ownership and efficiency in Swedish electricity distribution are not conclusive. Using stochastic frontier analysis on a panel data set from 2000-2007, Söderberg (2011) finds that private ownership is associated with lower costs than public ownership, although this finding is sensitive to modeling choices. Using data from 1970-1990, Kumbhakar and Hjalmarsson (1998) find that private ownership is on average associated with higher labor efficiency than public ownership. However, they find no conclusive evidence that labor efficiency increased more among the privately owned networks relative to the publicly owned networks. In contrast to the present study, none of the previous studies use ownership changes as the identifying source of variation. International experience also does not provide any clear cut predictions. Borghi et al. (2016) study the interaction effects between quality of government and private ownership in determining the total factor productivity of electricity distribution firms using data from $16 \mathrm{EU}$ countries. When the quality of government is poor, they find that private ownership is associated with higher productivity levels relative to public ownership. However, when the quality of government is high, private ownership is instead associated with lower productivity. In the context of U.S. electricity distribution, Kwoka (2005) finds that public ownership is more efficient, mainly due to a higher quality of service. In a study using data from 14 Latin American countries, Estache and Rossi (2005) find that the relative labor efficiency of private firms depend on the regulatory regime: private firms 
perform better under price cap regulation, but not under rate-of-return regulation.

\section{Institutional background and data}

\section{$2.1 \quad$ Regulatory framework}

Traditionally, a majority of the Swedish distribution networks have been owned by the municipalities, or by private firms organized as economic associations owned by the electricity consumers in the area where they operated. Some distribution networks were also owned by the state-owned firm Vattenfall, which is also the largest electricity producer in the Nordic region. Before the liberalization of the wholesale market in 1996, a proper incentive regulation for the distribution sector was not considered necessary, although there was a general legal principle stating that publicly owned firms were not allowed to make profits (självkostnadsprincipen). The not-for-profit rule did not apply to private firms, that in theory were free to set their own prices. However, under the Electricity Act a consumer could complain about the prices to the National Industrial Board, which involved approximately 25 cases per year (Kumbhakar and Hjalmarsson, 1998). Shortly after the liberalization of the wholesale market, a new regulatory framework was introduced. It was a type of rate-of-return regulation, albeit without being any more precise than that prices should be fair (skäliga). Heden (2012) characterizes the evaluation of the tariffs as "pretty ad-hoc", noting that "There wasn't any well defined methods for valuation of the distribution firms' assets, or explicit principles for what would constitute a fair rate-of-return".

There are several reasons why a traditional rate-of-return regulation may fail to incentivize firms to minimize costs. The most well-known is attributed to Averch and Johnson (1962), showing that firms have incentives to engage in excessive amounts of capital accumulation in order to expand the volume of profits. Laffont and Tirole (1993) discuss how information asymmetries between the regulator and the firm under rate-of-return regulation can lead to several other inefficiencies. Even though the switch from rate-ofreturn to incentive regulation took place in tandem with the liberalization process in most countries, the insight that also public bureaucrats seek to maximize their own budgets 
suggests that a proper incentive regulation may increase efficiency also among publicly owned firms (Niskanen, 1968).

One of the ways to get around the misguided incentives provided by traditional regulation is to benchmark firms against each other, in order to achieve a type of artificial yardstick competition (Shleifer, 1985). In the electricity distribution sector, different forms of yardstick regulation have been adopted by countries such as Norway, Australia, and UK. In these models, a best-practice frontier of real firms is identified, against which individual firms can be compared (Jamasb and Pollitt, 2008).

In 2003, Sweden also adopted a proper incentive regulation. However, instead of benchmarking costs against other firms, the allowed revenue was determined to reflect the cost of building and operating a hypothetical network with the same exogenous environmental and demand conditions as the real network. It was called the Network Performance Assessment Model (NPAM). Similar "reference firm" regulations have also been adopted by Chile and Spain (Jamasb and Pollitt, 2008). Sweden formally abandoned the NPAM in 2008 and adopted a revenue cap regulation that has been in place since 2012. During 2009-2011, there was a slight change in the NPAM regulation to facilitate the transition to the new regulation. During these years, the reference cost was computed based on the actual technical characteristics of the physical network, and there was a higher emphasis on price trends, as opposed to the static relationship between costs and price in each separate year (Energy Markets Inspectorate, 2012). The NPAM is described in more detail below. 


\section{The Network Performance Assessment Model}

The implementation of the NPAM can roughly be summarized by the following steps (the description has largely been adapted from Jamasb and Pollitt, 2008).

1. Data collection. Information about the geographical coordinates of customers and their consumption usage are collected, together with the coordinates of the network's connection points to neighboring and overlying regional networks.

2. Computation of reference network. The NPAM algorithm constructs a hypothetical reference network, including meters of line per exit point; a density measure to every meter of line; the capacity for every transformer station, and a density measure for every transformer.

3. Computation of reference network costs. The investment cost for each network is computed using the standard costs of equipment found in the Swedish Electricity Building Rationalization (EBR) catalogue. The costs of building and operating the network today are derived using cost functions for capital costs, return on capital, operation and maintenance, network administration, and network losses. The costs are also adjusted for quality of service in terms of supply interruptions.

4. Computation of charge rate and regulatory scrutiny. The revenue of the actual network is divided by the computed costs of the hypothetical reference network, obtaining the network's "charge rate". The charge rate is computed each year ex-post, and the comparison is made only with respect to the previous year's revenue. A charge rate lower than unity indicates that the firm is more efficient than its reference network. If the charge rate is above a certain threshold, the concession holder is subject to a detailed investigation. The trigger charge rate is determined ex-post by the regulator. In 2003 was 1.3, in 2004-2005 it was 1.2, and from 2006 and onwards it was 1.1. If the detailed investigation shows that the charges are justified, the case is closed. Otherwise, the concession holder is imposed to retrospectively lower prices and pay back customers.

Under the NPAM model, all firms could in theory be subject to regulatory scrutiny, since the relative performance of the firms should not matter. However, the trigger charge rate 
is set ex-post depending on the choice of the regulator. Thus, it is likely that the trigger charge rate is set such that a "reasonable" share of the firms are exempted from regulatory scrutiny, adding an element of yardstick regulation also to the NPAM model. Further, the use of the EBR catalogue as a determinant of the investment cost of each network adds another element of yardstick regulation to the model, since the costs in the EBR catalogue are determined by actual costs reported by all firms in the industry. It should be noted that the EBR catalogue not only serves as a reference for the cost of physical equipment, but also contains estimates of the number of hours needed to install different types of equipment ${ }^{1}$. Jamasb and Söderberg (2010) examine how network owners have responded to the incentives given by the NPAM regulation, finding that owners respond by inflating (reducing) their costs when they have low (high) charge rates.

Although the long term goal of the NPAM was to make actual revenues contingent entirely on exogenous characteristics that the firms were unable to influence, in this respect the NPAM was not successful. Out of the 16 firms (including Fortum and E.ON) that were imposed to pay back customers after the first round of scrutiny, all of the firms appealed to a higher court. After a lengthy legal process, the firms agreed to pay back parts of their revenues in 2008, amounting to 140 million SEK (Heden, 2012).

\subsection{Electricity distribution in Sweden}

The Swedish electricity supply chain is physically divided into four vertically separated markets: generation, national transmission, regional transmission, and distribution. A schematic diagram is presented in Figure A1. The wholesale market for electricity is organized on the Nordic power exchange Nord Pool. E.ON and Fortum are important players in all markets except for national transmission, which is completely controlled by the state-owned transmission system operator Svenska Kraftnät. The scope of this paper is limited to the distribution network, which has the lowest voltage and connects end consumers to the system. However, the regional transmission network is subject to the same type of regulation as the distribution network, and is almost exclusively controlled by Vattenfall, E.ON, and Fortum. In a review of the empirical literature,

\footnotetext{
${ }^{1}$ The risks of coordination on manipulation of costs in the EBR catalogue are impending, and has been noted by the Swedish Competition Authority (2003) and Jamasb and Pollitt (2008).
} 
Meyer (2011) documents a range of studies from several countries finding economically significant economies of scope between various stages in the supply chain. Although it is beyond the scope of this paper to quantify its importance in the present setting, one should bear in mind that the regulatory structure does not take economies of scope into consideration, which should provide E.ON and Fortum with a cost advantage compared to municipality owned networks that generally do not engage in generation or regional transmission (although some of the municipality owned firms also own some generation units).

The distribution network is geographically divided into concession areas, which legally define each local monopoly by its geographical boundaries. The concession areas are the relevant legal unit when computing the charge rates. Hence, technical and accounting data are available by concession area. Henceforth, I will simply refer to a concession area as a network. Each network can only be operated by one firm, but one firm can be the operator in several networks. If a firm acquires several bordering networks, they are merged into one. Therefore, although 34 publicly owned networks were acquired, complete panel data can only be constructed for five networks (four for Fortum and one for E.ON). Therefore, these networks are much larger than the other networks in the panel data structure, which is discussed further below.

E.ON is a privately owned, publicly traded German energy firm. Fortum is also publicly traded, but the Finnish government owns 51 percent of the shares. However, as there is no reason to believe that the Finnish government would have preferences for Swedish consumer surplus, in the present setting I assume that it behaves as a profit maximizer. E.ON entered the market in 2001, acquiring the majority share in the Swedish firm Sydkraft, which owned both distribution networks and generation. Prior to the acquisition, the combined ownership of the Swedish municipalities Malmö, Oskarshamn, Lund, Landskrona, and Halmstad constituted the greatest voting share in Sydkraft. In 2004 E.ON also acquired the firm Graninge. However, since Graninge was already privately owned, this concession area is excluded from the main specification (including this area does not affect the main results). Fortum was already present in the Swedish market at the beginning of the sample period. However, it was only in 2002 that it became the majority owner in Birka Energy, which it previously co-owned together with Stockholm municipality. During 
the following two years, E.ON and Fortum also acquired a few more municipality owned networks, but those networks were minor in comparison to the ones owned by Sydkraft and Birka Energy. By the end of the sample period, E.ON had a market share of 20 percent (measured by the number of residential customers), while Fortum and Vattenfall had a market share of 18 percent each. The fourth largest player in the market is the municipality owned Göteborg Energi, with a market share of five percent. Vattenfall did not make any major acquisitions during the sample period. Even though Vattenfall is owned by the Swedish government, Vattenfall may still behave as a profit maximizer as there is no direct link between the local community and Vattenfall. Evidence in line with this view has been found by Muren (2011). In a study of the pricing of Swedish district heating, she finds that large firms like Vattenfall charge relatively higher prices than small firms, even when the large firms are publicly owned. I therefore exclude Vattenfall from the control group, since the control group should ideally only contain firms that are not profit maximizers.

Figure 1 depicts the geographical locations of the networks owned by the three largest firms in 2011. All three firms control parts of the distribution network in Stockholm, which is the capital and the most densely populated area. 30 percent of the remaining networks are operated by private firms. 70 percent of the private firms are economic associations (ekonomiska föreningar), owned by the electricity consumers themselves. In total, there are 105 control networks owned by the municipalities. It is not evident that the economic associations are suitable as control groups. On the one hand, they are privately owned and could therefore be considered as profit maximizers. On the other hand, the owners are the local consumers, and they should therefore be fairly free from incentives of overcharging. In the main specification, I therefore remove these firms from the control group. However, including them does not have any major impact on the results. 
Figure 1: Network ownership by the three largest firms in 2011
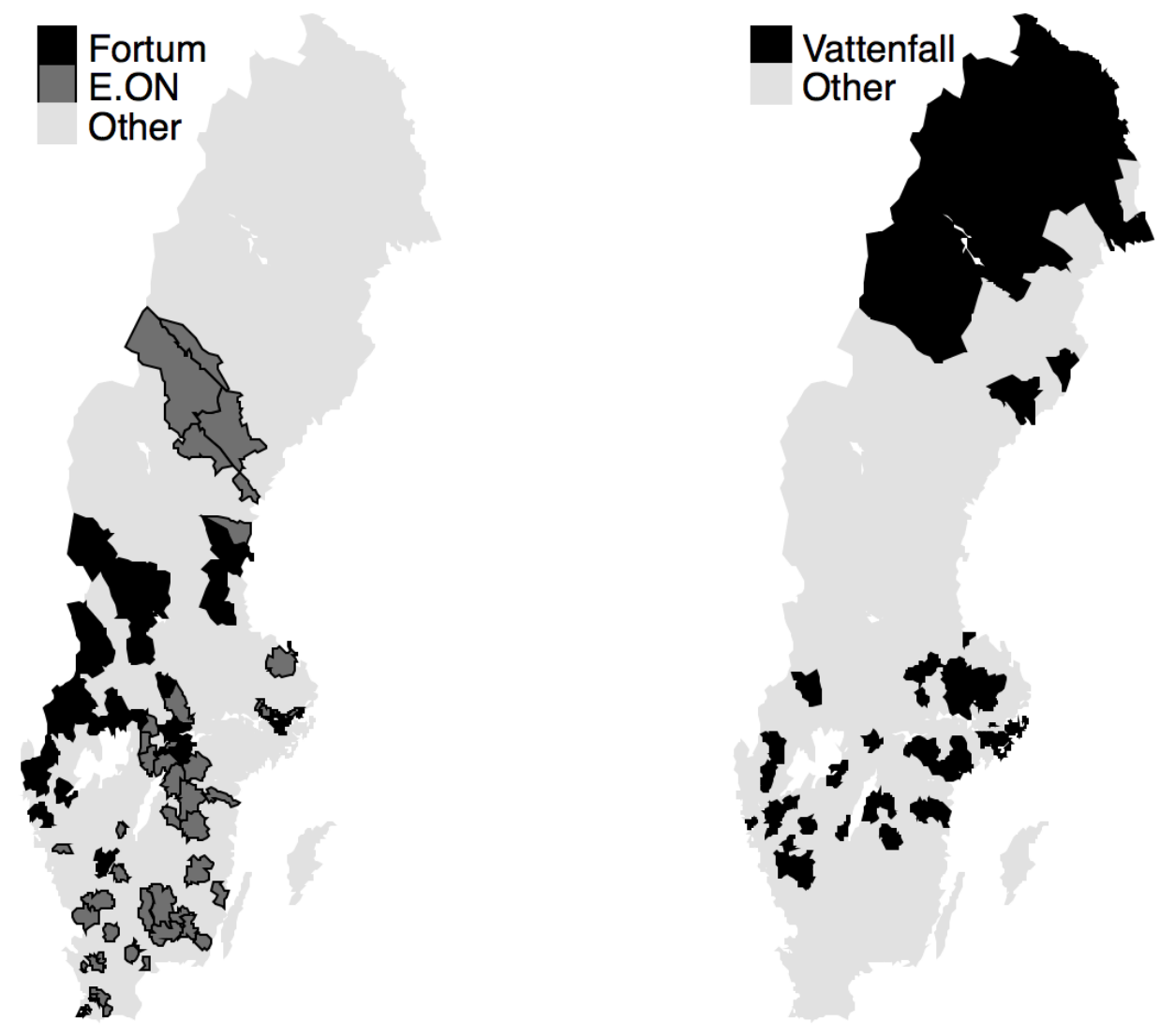

Note: This figure depicts networks owned by Fortum, E.ON, and Vattenfall in 2011. Also networks acquired from private firms are included. To prevent cluttering, the networks owned by Vattenfall are depicted in the right diagram.

\section{$2.3 \quad$ Data}

Data has been compiled by the Energy Markets Inspectorate, and is available on a yearly basis during 2000-2011. Some data for later years are available, but not enough to estimate the full model. The data set includes both accounting data and technical characteristics of the networks. Summary statistics of all variables are depicted in Table 1.

I measure output by the number of customers. Alternatively, total electricity consumption could have been used, but data on the number of customers has less missing observations ${ }^{2}$. Since the number of customers is exogenous (unless customers relocate due to high elec-

\footnotetext{
${ }^{2}$ For a small number of observations, data on the number of customers is missing or implausible. I then compute the value using linear interpolation between the closest years before and after the missing data point(s).
} 
tricity distribution prices), demand is inelastic. More than 99 percent of the customers in all networks are low-voltage customers, and the cross-sectional correlation between the number of low- and high voltage customers is above 0.93 for all years in the sample. Therefore, I do not distinguish between the two customer groups, although the cost of serving a high-voltage customer is likely to differ from the cost of serving a low-voltage customer. The control networks are all municipality owned networks that were not acquired by E.ON or Fortum. The acquired networks are all municipality owned networks that were acquired by E.ON or Fortum. Except for the number of customers, the distribution of the variables are relatively similar across groups. A category of data that would be useful to examine, but that is not available for the full sample period is quality of service, which is usually measured by the number and length of outages per customer.

The first outcome variable, price, is defined as revenue per customer and year (the only revenue source is payments from customers). Alternatively, the total price payed by a representative customer could be used, but since the price is a two-part tariff, the average revenue per customer should be more accurate. The average price over the whole sample is 4,300 $\mathrm{SEK} /$ customer (10 SEK $\approx 1 \mathrm{EUR}$ ). The mean nominal price increase during the sample period is 40 percent (20 percent in real terms). The greatest price increase was in 2010, which was on average 8 percent. The Energy Markets Inspectorate (2011) notes that the sharp increases during the later years in the sample are partly due to costs associated with two great storms in 2005 (Gudrun) and 2007 (Per). Tougher regulations to prevent outages, and obligations to offer hourly metering of consumption in 2009 are other possible contributing reasons. Further, the local distributors' fees to the national transmission network have increased due to a higher demand on the transmission lines as new wind power plants are incorporated in the system.

The second outcome variable, labor efficiency, is defined as the number of customers per unit of labor. However, to make the outcome variables comparable, instead of labor efficiency I will henceforth refer to its inverse, labor cost, which is expressed in SEK/customer. Examining the accounting data, the accounted cost for "Staff expenditures" only includes services produced in-house, and not the cost of services that have been outsourced. These services are instead accounted for as "Other external costs", according to the guidelines set by the regulator. Since outsourcing has become increasingly common, these costs 
Table 1: Summary statistics

\begin{tabular}{lcccc}
\hline \hline & \multicolumn{3}{c}{ Control netw. } & \multicolumn{2}{c}{ Acquired netw. } \\
& mean & sd & mean & sd \\
\hline Price (SEK per customer) & 4269 & 1193 & 4812 & 928 \\
Staff expenditures (SEK per customer) & 801 & 483 & 717 & 428 \\
Other external costs (SEK per customer) & 890 & 699 & 616 & 545 \\
Total labor cost (SEK per customer) & 1691 & 787 & 1333 & 402 \\
\hline Number of customers (thousands) & 22 & 73 & 190 & 167 \\
Density (overhead line meter per customer) & 56 & 46 & 78 & 43 \\
Density (ground line meter per customer) & 51 & 25 & 48 & 19 \\
Transformer stations per 10000 customers & 7 & 31 & 6 & 2 \\
Transformer capacity per customer & 281 & 3799 & 149 & 64 \\
\hline Observations & 1776 & & 60 & \\
\hline \hline
\end{tabular}

Note: This table depicts summary statistics of the municipality owned control networks that were not acquired (left), and the networks that were acquired by E.ON and Fortum (right).

should also be taken into account. Therefore, I include "Other external costs" in the labor cost. If the outsourced services instead would have been performed in-house, the wage cost of the service would be separated from the capital cost, such as renting maintenance equipment. A potential source of measurement error is therefore that the labor cost will be overestimated for firms that have a high degree outsourcing. Even in a fixed effects setting, this could lead to biased results as the share of outsourcing can differ between years within the same firm. To illustrate the substitutability between in-house and outsourced services, Figure A2 depicts the inverse trends for these items in the networks acquired by Fortum. The mean labor cost for the whole sample was 1,700 SEK/customer and year, which is about 40 percent of the price. The rest of the costs are mainly capital costs, and costs for electricity to cover transmission losses. The mean accounted operating profit (not reported in the summary statistics) is $601 \mathrm{SEK} /$ customer and year, which is about 14 percent of the price.

Figure 2 depicts the trends in price and labor cost for networks that were acquired, compared to the municipality owned networks that were not acquired. Figure A3 depicts the corresponding trend for networks owned by economic associations. Two years, 20072008 , stand out as the years with the highest labor costs in the acquired networks. This is partly due to the storm Per that swept through the south of Sweden in 2007 through several of the networks owned by E.ON and Fortum. Except for 2007-2008, the labor 
Figure 2: Trends in price and labor cost
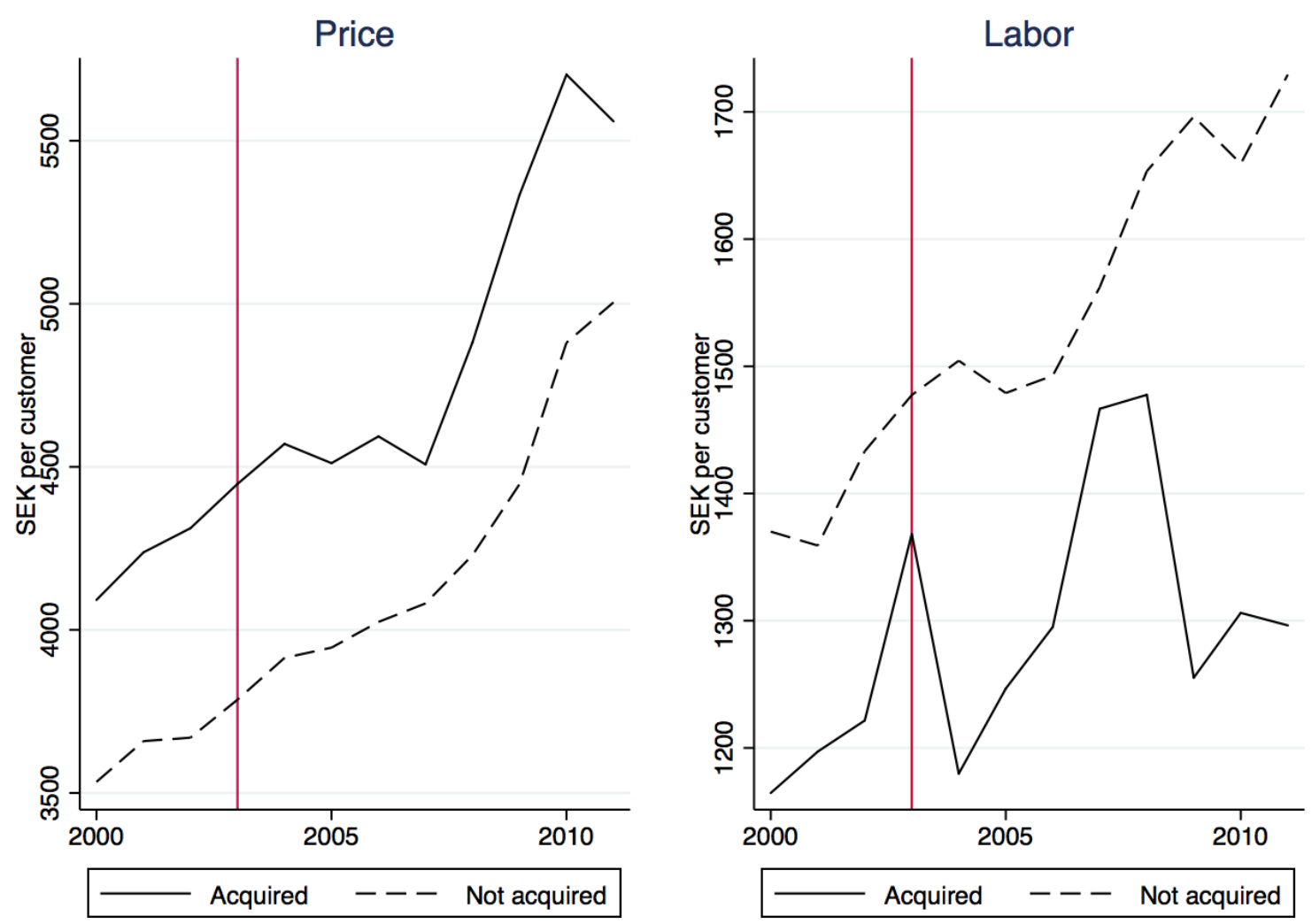

Note: The dashed lines depict the mean price and labor cost per customer for municipality owned control networks that were never acquired. The solid lines depict the same variables for networks that were acquired by Fortum or E.ON. The vertical line is in 2003. 
costs in the non-acquired networks increased comparatively more than in the acquired networks. Histograms of both outcome variables are depicted in Figure A4.

Among the technical characteristics of the network, the most important cost driver is network density. It is measured by meter of power line per customer. There are two categories of power lines: overhead lines, that are suspended by poles, and lines that are submerged under ground. Overhead lines generally demand more maintenance, and should thus be a more important determinant of labor cost than ground lines (although the initial investment cost is usually higher for underground lines). Other technical characteristics include the number of transformers per customer and the total transformer capacity per customer. The variable measuring economies of scale is the number of customers. Economies of scale arise when the average cost is decreasing in the number of customers served, while network density is kept constant. This variable is almost ten times higher for the acquired networks than for the non-acquired networks, since this figure refers to the number of customers in the merged networks after the acquisitions took place. The mean number of customers in the acquired networks during the pre-acquisition period is 21,000 (the median is 16,000 ), which very similar to the corresponding figure for the non-acquired networks.

\section{How accurate is accounting data?}

A disadvantage of relying on accounting data is that firms may have incentives of misreporting, see e.g., Balakrishnan et al. (2012) for evidence on how incentives of financial misreporting are strengthened in markets with imperfect competition. In the present context, firms have incentives of exaggerating their true costs in order to increase their allowed revenue. Even if the NPAM is based on exogenous variables only, there is still a possibility to renegotiate the allowed revenue with the regulator ex post. For firms that wish to cross-subsidize divisions that are not subject to regulation, incentives of misreporting may be even stronger, e.g., by letting the administrative staff handle the tasks of the firm's retailing activities, or by letting maintenance staff perform maintenance on equipment owned by the firm's generation division. Even for firms with low charge rates, this may be a beneficial strategy if firms believe that regulation will be tightened if the 
regulator finds profits to be unreasonably high. As discussed above, Jamasb and Söderberg (2010) find evidence that firms with low charge rates tend to inflate their costs. For Fortum, E.ON and Vattenfall, the possibilities of cross-subsidization should be even greater since these are the only firms that also operate the regional transmission networks. The regional transmission networks are also subject to the NPAM, and these networks are usually located in the same region as the distribution networks. Since the type of costs associated with regional transmission and distribution are similar, it should be relatively easy to transfer costs to the division with the lowest charge rate. A similar argument can be made for firms operating several distribution networks.

Municipalities were not allowed to finance public expenditures through network profits during the sample period, although some of them openly did so without receiving any penalties (SVT, 2015), which could strengthen incentives of misreporting among the municipality owned networks. It could also enhance incentives to inflate costs through overstaffing if the network has a low charge rate and the municipality wishes to increase employment. The prohibition against financing public expenditures through network profits was a remnant from the pre-liberalization "not-for-profit" rule, which was put in place to prevent municipalities from using electricity pricing as an instrument of taxation. In 2015, the Supreme Administrative Court (2015) decided that network profits could be used to finance public expenditures in contradistinction to earlier decisions by the lower court, which should have mitigated incentives for municipalities to transfer costs to the network division of the municipality.

Further, incentives to understate costs may arise among owners that are planning to divest their network, as higher profitability should appear more attractive to investors. In the present context, this could be relevant to Fortum that in 2015 divested all its distribution and regional transmission networks to a consortium lead by the Canadian firm Borealis Infrastructure (SvD, 2015). The price tag was approximately 7,000 EUR per residential customer (or 6.6 billion EUR in total). To get a rough idea if the accounted profits appear reasonable in relationship to the price, back-of-the envelope calculations suggest that the highest discount rate that could justify the investment given a perpetuity corresponding to the accounted EBITDA is 2.7 percent $^{3}$. However, the figure appears to be rather low,

\footnotetext{
${ }^{3}$ In 2011, Fortum's EBITDA was 190 EUR per residential customer (including the earnings on the
} 
indicating that accounted costs could be overstated, and possibly that the acquirer was aware of this. By comparison, the benchmark repo interest rate set by the central bank of Sweden averaged at 3.46 percent during the last two decades.

In sum, there are several reasons why accounting data should be interpreted with care, and incentives of misreporting could exist in both directions depending on the individual circumstances of each firm. However, as the revenues of the firms consist exclusively of payments from customers that is relatively easy for the regulator to verify, the accounted revenues are likely to be more accurately reported than the labor costs.

\section{Method}

\subsection{The synthetic control method}

The conventional reduced form analysis when assessing the impact of an intervention, such as an acquisition, relies on the DID estimator. However, the DID estimator rests on assumptions that are often not met. First, the DID estimator is biased in the presence of time-varying unobserved confounders. Second, the DID estimator cannot determine which of the non-acquired networks that are most suited as controls, giving all nonacquired networks equal weight in the estimation process. This may not be desirable if some of the non-acquired networks are more similar to the acquired network, and therefore would be more suitable as controls.

The synthetic control method addresses these problems by constructing a synthetic control network from a weighted combination of the non-acquired networks, such that the trajectory of the outcome variable and the mean of the control variables in the synthetic network match the acquired network during the pre-acquisition period. Borrowing from the matching literature, the set of all non-acquired networks are usually referred to as the "donor pool". Since individual weights are restricted to be positive and sum to one, the synthetic control network is constructed without any extrapolation outside the convex

regional transmission network). The highest discount factor that can justify the investment given a perpetuity of 190 EUR per year is 2.7 percent $(190 / 0.027 \approx 7,000)$. Figures for later out-of-sample years were only slightly different compared to the figures for 2011. 
hull of the data from the donor pool.

Formally, following the notation in Abadie et al. (2010), suppose that there are $J+1$ networks, and that only the first network is acquired. Since several networks were acquired, one could either construct a representative network, or estimate the acquisition effects separately for each network. As my main results are qualitatively invariant to the choice of method, in the baseline estimation I construct a representative network in order to simplify the exposition, although I also report network specific effects. To construct the representative acquired network, I begin by merging all acquired networks into one large network (containing both E.ON's and Fortum's networks). Since the technical characteristics are expressed as fractions of the number of customers, the fact that the size of the merged network is very large does not matter. However, since I also match on the the number of customers, I set the number of customers in the representative network to the median number of customers in the acquired networks prior to the acquisitions, which is around 16,000 .

Let $Y_{i t}^{A}$ and $Y_{i t}^{N}$ be the outcomes that would be observed for network $i$ at time $t$ given an acquisition, and in absence of an acquisition, respectively. Let $T_{0}$ be the number of pre-acquisition periods, with $1 \leq T_{0}<T$. Let $D_{i t}$ be an indicator that takes the value one if network $i$ has been acquired at time $t$, and zero otherwise. The observed outcome for the acquired network at time $t$ is then $Y_{1 t}=Y_{1 t}^{N}+\alpha_{1 t} D_{1 t}$. As the vector of interest is $\alpha_{1 t}$, we need to estimate $Y_{1 t}^{N}$ for all periods where we do not have observational data. Suppose that $Y_{i t}^{N}$ is given by the factor model

$$
Y_{i t}^{N}=\delta_{t}+\boldsymbol{\theta}_{t} \mathbf{Z}_{\mathbf{i}}+\boldsymbol{\lambda}_{t} \boldsymbol{\mu}_{\boldsymbol{i}}+\varepsilon_{i t}
$$

where $\delta_{t}$ is an unknown common factor with constant factor loadings across networks (cf. a time fixed effects vector in a DID setting), $\mathbf{Z}_{\mathbf{i}}$ is a vector of observed technical characteristics not affected by the intervention, and $\boldsymbol{\theta}_{\boldsymbol{t}}$ is a vector of unknown parameters. Further, $\lambda_{t}$ is a vector of unobserved common characteristics, and $\mu_{i}$ is a vector of unknown factor loadings. In a DID setting, the "parallel trends" assumption is the identifying assumption ensuring that time-varying unobserved variables do not bias the results. By contrast, the synthetic control method takes advantage of the fact that there are several networks in 
the donor pool, and uses a matching algorithm that forces the parallel trends assumption to hold.

Ideally, the variables in $\mathbf{Z}_{\mathbf{i}}$ should be completely exogenous. In the short run, exogeneity seems reasonable. However, in this case it is not possible to determine wether the choice of technical characteristics is compatible with long run cost minimization, but rather if labor use is efficient given the set of technical characteristics. If long run efficiency is of interest, it could be more suitable to instead match only on purely exogenous environmental and demand characteristics (such as the number of customers and size of the concession area). In the framework of the NPAM regulation, this would be equivalent to match on the variables collected in the "data collection" stage. However, an implicit assumption is then that network owners are free to change the physical constituents of the network, and that there is a unique optimal network for a given set of environmental and demand characteristics. These assumptions are questionable, and have been contested by Jamasb and Pollitt (2008). In another study of the Swedish NPAM regulation, Jamasb and Söderberg (2010) find that the reference networks are not adequate representations of the real networks. Taken together, it appears most appropriate to keep the technical characteristics of the network as matching variables, at the expense of not knowing wether the technical characteristics of the networks have been chosen to optimize long term efficiency.

Consider a $(\mathrm{J} \times 1)$ vector of weights $\mathbf{W}=\left(w_{2}, \ldots, w_{J+1}\right)^{\prime}$ such that $w_{j} \geq 0$ for $j=2, \ldots, J+1$ and $w_{2}+\cdots+w_{J+1}=1$. That is, each particular value of the vector $\mathbf{W}$ represents a potential synthetic control group. The value of the outcome variable for each synthetic control indexed by $\mathbf{W}$ is:

$$
\sum_{j=2}^{J+1} w_{j} Y_{j t}^{N}=\delta_{t}+\boldsymbol{\theta}_{\boldsymbol{t}} \sum_{j=2}^{J+1} w_{j} \mathbf{Z}_{\mathbf{j}}+\boldsymbol{\lambda}_{\boldsymbol{t}} \sum_{j=2}^{J+1} w_{j} \boldsymbol{\mu}_{\boldsymbol{i}}+\sum_{j=2}^{J+1} w_{j} \varepsilon_{j t}
$$

Suppose that there is a vector of weights $\mathbf{W}^{*}$ such that 


$$
\begin{array}{r}
\sum_{j=2}^{J+1} w_{j}^{*} Y_{j 1}=Y_{1 t} \quad \forall t \leq T_{0} \\
\sum_{j=2}^{J+1} w_{j}^{*} \mathbf{Z}_{\mathbf{j}}=\mathbf{Z}_{\mathbf{1}}
\end{array}
$$

i.e., the synthetic control group matches the acquired network both in terms of the pretreatment trajectory of the outcome variable, and the observed technical characteristics. Then, Abadie et al. (2010) proves that under fairly standard conditions on the unobserved factors:

$$
\hat{\alpha}_{1 t}=Y_{1 t}-\sum_{j=2}^{J+1} w_{j}^{*} Y_{j t}
$$

is an unbiased estimator of $\alpha_{1 t}$, and the mean estimated post-treatment effect is then computed according to $\bar{\alpha}_{1}=\frac{1}{T-T_{0}} \sum_{t>T_{0}} \hat{\alpha}_{1 t}$. In practice, it is often the case that no set of weights exist such that (3) holds exactly. Then, weights are chosen to minimize the mean squared prediction error between the matrix of pre-acquisition characteristics and outcome variable trajectory of the real network, and the corresponding matrix of its synthetic control network.

To determine the precision of $\hat{\alpha}_{1 t}$, an inference method akin to the placebo tests used in the conventional DID setting is employed, by iteratively applying the synthetic control method to every network in the donor pool. Then, the mean estimated effect is computed for each placebo run. This iterative procedure provides a distribution of the estimated gaps for the networks that were not acquired. One can then compute the probability that a network chosen at random would produce an estimate at least the size of the estimated effect of the acquired network. In accordance with Abadie et al. (2010), I remove placebo networks with more than twice the mean squared prediction error of the original acquired network, as a large error indicates that the algorithm for finding a proper synthetic analogue did not succeed ${ }^{4}$.

In the present setting, a potential caveat is that the number of pre-treatment periods are rather small. To increase the number of pre-treatment periods, I assume that the

\footnotetext{
${ }^{4}$ I estimate the model using Stata's synth package (?).
} 
acquirers could not influence the outcome variables until one year after the acquisitions took place. This is a plausible assumption, as prices are usually revised only once a year, and revisions do not come in effect until at least couple months after the decision. An analogous reasoning can be made in terms of labor costs. A second issue is that E.ON acquired its networks approximately half a year before Fortum (in May 2001 and January 2002 respectively). Therefore, I estimated the model using both 2002 and 2003 as the year of treatment, without any qualitative change in results. In the main specification, I use 2003 as the year of treatment. Naturally, when estimating network specific effects, I instead use 2002 as the year of treatment for the networks acquired by E.ON.

\subsection{Accounting for economies of scale when firms acquire border- ing networks}

An identifying assumption of the synthetic control method is that the acquisition cannot affect the observed predictor variables $\left(\mathbf{Z}_{\mathbf{i}}\right)$. While this assumption appears acceptable for most physical characteristics of the network at least in the short run, it is clearly violated if the acquirer is able to enjoy increased economies of scale. For example, the acquirer may be able to use the same administrative staff for several networks, or optimize the use of equipment by transporting it between different regions. Failing to account for such synergies will bias the estimates of the causal efficiency gains of privatization upwards. However, it should be noted that previous studies have found that economies of scale in electricity distribution are limited, and that the main cost driver in electricity distribution is instead economies of density. For example, Hjalmarsson and Veiderpass (1992) study Swedish electricity distribution using cross-sectional data from 1985, finding that economies of scale are considerably less important than economies of density. Further, Salvanes and Tjøtta (1994), also using cross-sectional data, studies Norwegian distribution networks finding economies of scale only for networks with less than 20,000 customers. 


\section{Difference-in-differences estimation}

Despite its inability to account for unobserved time-varying characteristics, an advantage of the DID estimator is that the observed control variables are allowed to vary as a response to the acquisitions, enabling the estimation of increased economies of scale when several networks are acquired. The DID estimator is identified by:

$$
y_{i t}=\alpha+\rho_{a}+\boldsymbol{\lambda}_{t}+\delta D_{a t}+\mathbf{X}_{i t} \gamma+\varepsilon_{i t}
$$

Where $y_{i t}$ is the outcome variable in network $i$ in year $t$, and $\alpha$ is a constant. The dummy variable $\rho_{a}$ takes the value one if the network was acquired ${ }^{5} . \boldsymbol{\lambda}_{t}$ is a vector of year fixed effects, and $\mathbf{X}_{i t}$ is a matrix of time-varying control variables with its associated coefficient vector $\boldsymbol{\gamma} . \mathbf{X}_{i t}$ contains the same physical characteristics as $\mathbf{Z}_{\mathbf{i}}$ in equation (1). Due to potential problems with multicollinearity, I add the underground and overground lines to obtain one single variable. The coefficient of interest is $\delta$, capturing the effect of the acquisition dummy variable $D_{a t}$, which takes the value one for all acquired networks in the post-acquisition period, and zero otherwise. Standard errors are clustered by network.

Looking at Figure 1, it is evident that the acquired networks are dispersed. However, for each firm there are also some of the acquired networks that share borders, and I assume that economies of scale can be realized only among the neighboring networks ${ }^{6}$. In terms of accounting units, all bordering networks sharing the same owner have been merged to one unified network at some point during the sample period. On average, there are seven sub-networks within each of the five unified networks. Since panel data can only be constructed for the unified networks, I begin by duplicating each of the unified networks

\footnotetext{
${ }^{5}$ Alternatively, the model could be estimated using a full set of network fixed effects. However, in that case the coefficient on the number of customers would rely on within-network variation only. Then, scale effects in the control networks cannot be identified, as that would in practice require that unpopulated regions became populated during the sample period.

${ }^{6} \mathrm{~A}$ complicating factor is that some of the bordering networks shared the same owner already before the acquisitions. However, in the majority of these cases, a previous acquisition had been made shortly before the network was acquired by E.ON or Fortum. For example, Sydkraft acquired numerous municipality owned networks between 1999-2001, which is the reason why most of these networks remained separate accounting units up until 2003. For a comprehensive review of all major M\&As in the Swedish electricity market 1997-2006, see Energy Markets Inspectorate (2006).
} 
as many times as the original number of sub-networks. Data on the number of customers in the pre-acquisition period is then replaced by the observed number of customers in each of the sub-networks. Suppose that network A (1 customer) and network B (99 customers) are merged into network C (100 customers). In the period following the acquisition, both network A and B will have 100 customers. All other other data entries are kept intact. A complicating factor in estimating the effect using a DID estimator is that each of the smaller networks are given equal weights in the estimation process. In the example above, it is obvious that almost no scale effects can be realized. Therefore, I estimate the model using analytical weights, based on the number of customers in $2000^{7}$. The model produces coefficients with identical magnitudes as if there would have been one observation for each customer in the whole system, while leaving the sample size and standard errors unchanged. In reality it may take a while before scale effects can be realized, due to labor market regulations, long delivery periods for equipment, etc. Therefore, I perform robustness tests assuming that there is a lag in how quickly scale effects can be realized.

\section{Results}

\subsection{Results from the synthetic control method}

Table 2 shows the pre-acquisition mean of the matched variables in the real acquired network and the synthetic control network respectively. The variables in the real acquired network match the variables in the synthetic networks very well. Importantly, both outcome variables are matched very well, with an absolute difference compared to the real network of less than one percent.

The upper left diagram in Figure 3 compares the trajectory of the price in the acquired network to its synthetic analogue. Both the real and the synthetic network experience an increase in price of around 40 percent throughout the sample period, which is about the same as the industry average. In the first years following the acquisitions, the price

\footnotetext{
${ }^{7}$ I estimated the model using Stata's aweight command. Weights have been normalized across groups so that the mean weight of an acquired network equals the mean weight of a non-acquired network.
} 
Table 2: Price and labor cost predictor means

\begin{tabular}{lccc}
\hline \hline & $\begin{array}{c}\text { Acquired } \\
\text { mean }\end{array}$ & $\begin{array}{c}\text { Synth. (Price) } \\
\text { mean }\end{array}$ & $\begin{array}{c}\text { Synth. (Labor) } \\
\text { mean }\end{array}$ \\
\hline Density (overhead line) & 71.43 & 71.66 & 71.30 \\
Density (ground line) & 43.62 & 43.87 & 43.52 \\
Transformer stations & 4.27 & 4.29 & 4.27 \\
Transformer capacity & 9.46 & 8.87 & 9.25 \\
Number of customers & 16.23 & 16.15 & 16.32 \\
\hline Price in 2002 & 4237.76 &. & 4242.48 \\
Labor cost in 2002 & 1197.10 & 1203.20 &. \\
\hline \hline
\end{tabular}

Note: This table depicts the mean of the predictor variables, including the outcome variables in 2002 .

in the acquired network is somewhat lower than the synthetic price. This indicates that new owners keep prices low for a number of years after the acquisition, possibly to reduce the risk of being suspected of overcharging, either by the consumers or the regulator. In 2008, the price in the acquired network started to catch up with the synthetic price, and by the end of the sample period the price in the acquired network was 2 percent higher (corresponding to $175 \mathrm{SEK} /$ customer). Thus, the result gives some support to the views expressed by consumer groups that prices in the acquired networks have increased more than comparable publicly owned networks, given that the period of interest is 20082011. However, on average the price in the acquired network is 1.3 percent below the synthetic network during the years following the acquisitions, an effect that is hardly economically significant. The trajectories of the placebo effects in the 73 out of 105 control networks with a mean squared predicted error below the threshold are depicted in Figure A5. The distribution of the placebo estimates also confirm that the effect is not statistically significant, as the estimated effect of -1.3 percent belongs to the $5^{\text {th }}$ decile of the distribution. The trajectories for the full placebo sample are depicted in Figure A6.

One interpretation of the zero effect on the price is that the regulation has been effective, as the acquirers have not been able to push up the price even though it would lead to higher profits. It may also be that the acquirers are afraid that increased prices would lead to more strict regulations in the future.

The upper right diagram in Figure 3 compares the trajectory of the labor cost in the 
Figure 3: Effect of acquisitions on price and labor cost
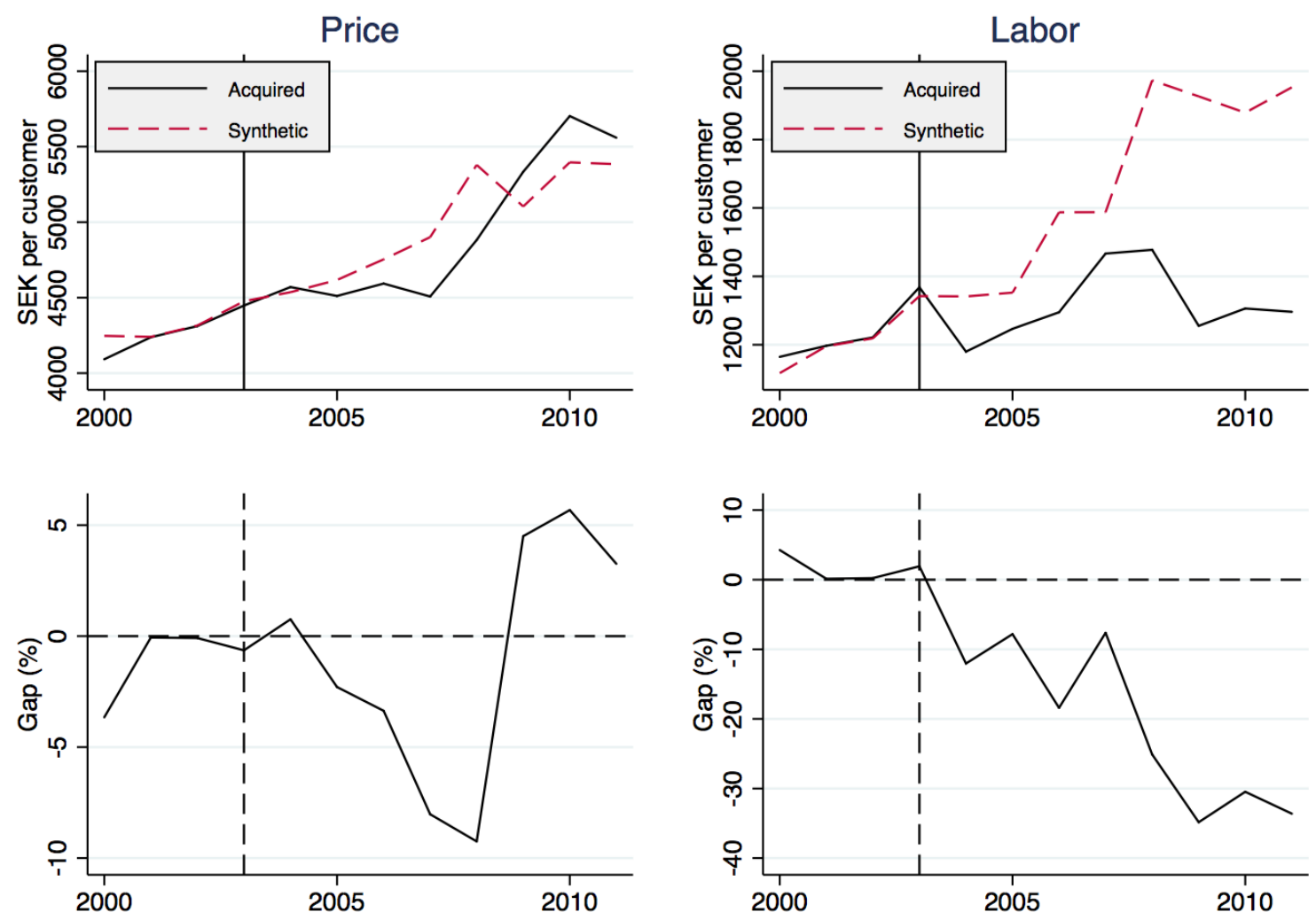

Note: First row: Trajectory of outcome variables for the real representative acquired network and the corresponding synthetic network in SEK/customer. Second row: Outcome gaps between the real representative network and the corresponding synthetic network, expressed as a percentage of the real observed outcome variable. 
acquired network to its synthetic analogue. In contrast to the price, the trajectories differ substantially, and the average acquisition effect is -18 percent, or correspondingly -360 SEK per customer. The effect is mainly driven by a sharp increase in the labor cost of the synthetic network. The gap is depicted in the bottom right diagram of Figure 3, where it is clear that the effect has increased over time. This is expected, since it should take some time to change the organizational structure of the networks due to labor regulations etc. The trajectory of the placebo effects are depicted in Figure A5. None of the estimates of the 37 networks in the placebo group which had a mean squared prediction error below the threshold are lower than the estimated real effect. Since there are 37 networks in the placebo sample, this means that the chance of randomly estimating an effect as large as the real estimated effect is less than five percent.

\section{Network specific effects}

Network specific effects are presented in Table 3, and trajectories of the outcome variables are depicted in Figure 4 and 5. Results are broadly in line with the results using the representative network. The price effect in each of the networks is small, and the average effect is an increase in the price of 1.4 percent. The largest effect of 6.6 percent is found in Fortum's network 2, but in comparison to the placebo estimates the effect is still not significant. The effect on labor cost is negative for all networks, although the networks acquired by Fortum have experienced a comparatively larger reduction in labor costs. In this light, it appears plausible that the storm Per in 2007 did fact inflate the labor costs of E.ON, as the observed labor cost in 2007 is larger than for any other year. The mean effect across all networks at -25 percent is somewhat larger than the estimated effect when only considering one representative network. 
Table 3: Network specific effects

\begin{tabular}{lcc}
\hline \hline & $\begin{array}{c}\text { Labor cost } \\
\text { mean }\end{array}$ & $\begin{array}{c}\text { Price } \\
\text { mean }\end{array}$ \\
\hline E.ON (network 1) & -4.9 & 2.6 \\
Fortum (network 1) & -27.9 & 0.3 \\
Fortum (network 2) & -34.1 & 6.6 \\
Fortum (network 3) & -25.4 & 1.5 \\
Fortum (network 4) & -31.7 & -3.8 \\
\hline Mean across networks & -24.8 & 1.4 \\
\hline \hline
\end{tabular}

Note: Network specific effects, expressed as percentage gaps compared to the synthetic networks.

Figure 4: Network specific effects on price
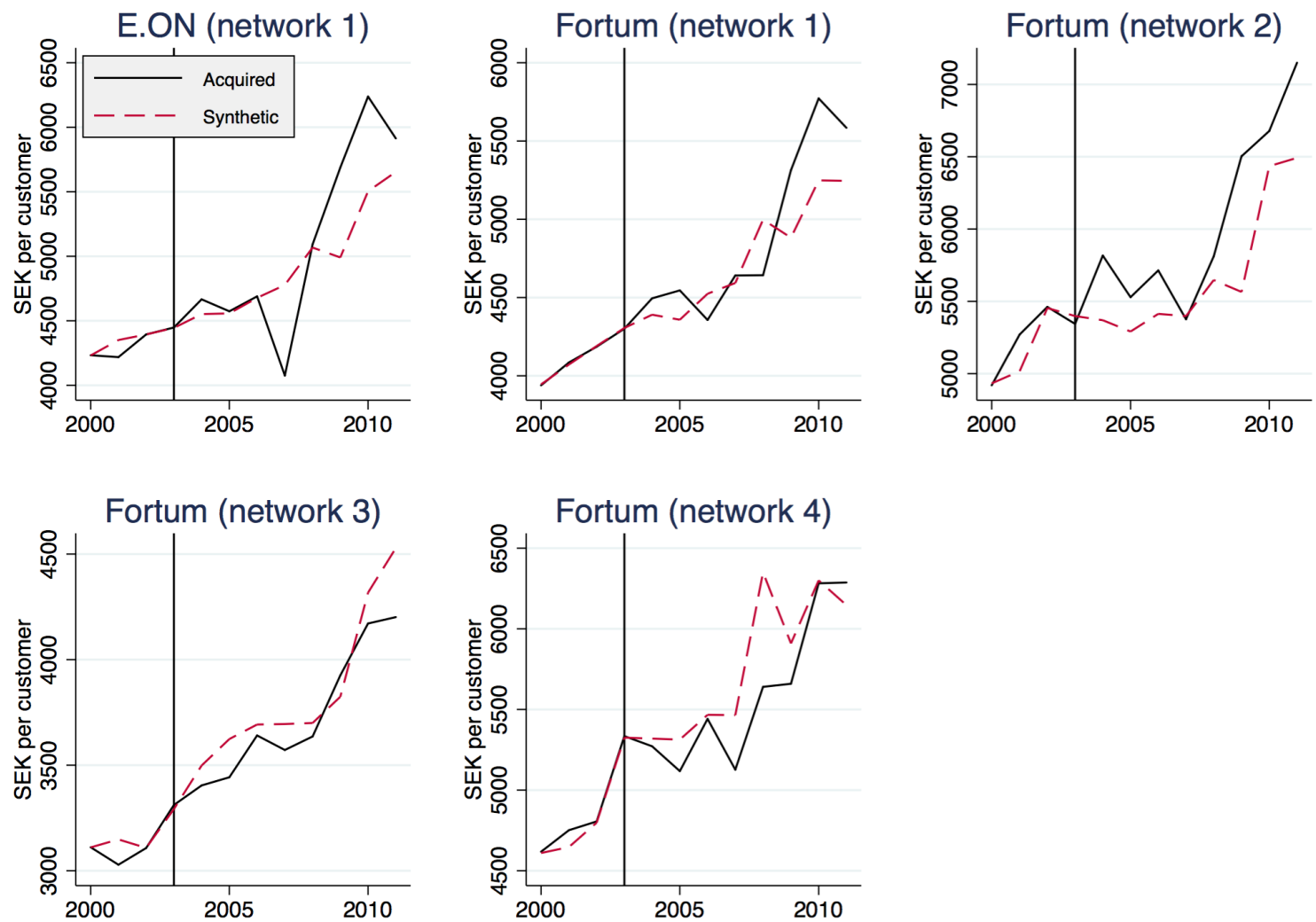

Note: Trajectory of the price in the real acquired networks and the corresponding synthetic networks in SEK/customer. 
Figure 5: Network specific effects on labor cost
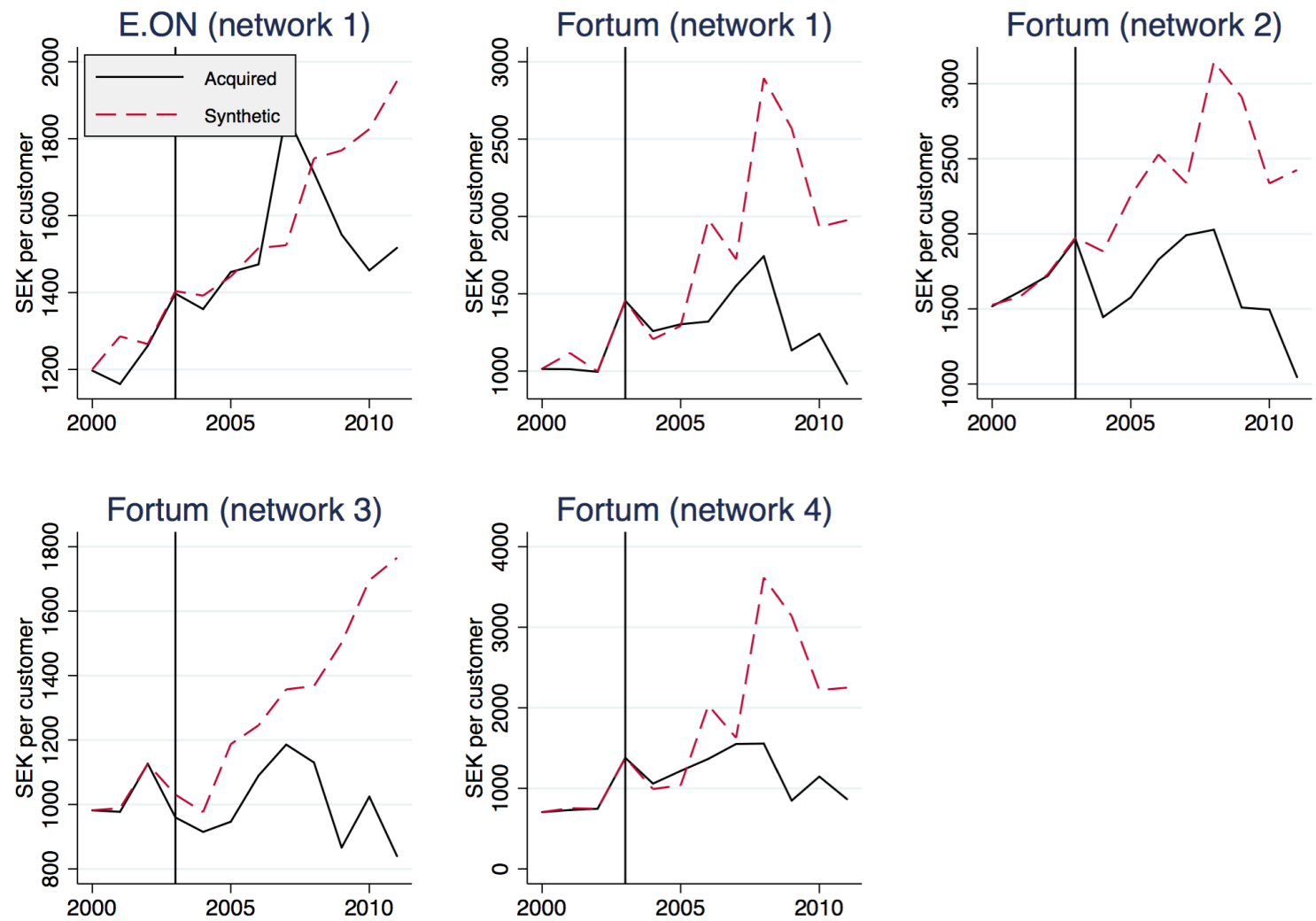

Note: Trajectory of the labor cost in the real acquired networks and the corresponding synthetic networks in $\mathrm{SEK} /$ customer.

\subsection{Results from the difference-in-differences estimation}

The first two columns in Table 4 depicts the results assuming that scale effects could be realized immediately at the time of the acquisitions. The acquisition effect on both price and labor are now positive, at 7 and 16 percent respectively, in contrast to the results from the synthetic control method. The new results indicate that the acquirers have not been able to realize the economies of scale that would be theoretically possible. However, there are several caveats associated with this result. First, as discussed above, it is not likely that scale effects can be realized immediately. Therefore, in columns (3) and (4) I do not increase the number of customers in the acquired networks until in 2007, to allow for four years to adapt to the new circumstances. Both effects now drop by half, but are still both statistically and economically significant. Still, since the publicly owned control 
networks have substantially fewer number of customers than the acquired networks, the results rely on extrapolating the estimated scale effect to networks larger than the control networks, which is another reason why results should be interpreted with care.

Table 4: Difference-in-differences estimates.

\begin{tabular}{lcccc}
\hline & $\begin{array}{c}(1) \\
\text { Price }\end{array}$ & $\begin{array}{c}(2) \\
\text { Labor }\end{array}$ & $\begin{array}{c}(3) \\
\text { Price }\end{array}$ & $\begin{array}{c}(4) \\
\text { Labor }\end{array}$ \\
\hline Acquisition effect $(\hat{\delta})$ & $0.069^{* *}$ & $0.16^{* *}$ & $0.029^{*}$ & $0.081^{*}$ \\
& $(0.034)$ & $(0.069)$ & $(0.017)$ & $(0.046)$ \\
Customers & $-0.037^{* *}$ & $-0.088^{* * *}$ & $-0.031^{* *}$ & $-0.092^{* * *}$ \\
& $(0.017)$ & $(0.025)$ & $(0.015)$ & $(0.024)$ \\
Density & $0.17^{* * *}$ & $0.21^{* * *}$ & $0.17^{* * *}$ & $0.20^{* * *}$ \\
& $(0.040)$ & $(0.049)$ & $(0.041)$ & $(0.050)$ \\
Transformer stations & 0.15 & 0.089 & 0.15 & 0.089 \\
& $(0.098)$ & $(0.077)$ & $(0.099)$ & $(0.077)$ \\
\hline Observations & 1632 & 1632 & 1632 & 1632 \\
\hline$* 0<10{ }^{* *} p<0.05, * * *$ & $p<0.01$ & & &
\end{tabular}

${ }^{*} p<.10,{ }^{* *} p<0.05,{ }^{* * *} p<0.01$

Note: Dependent variables are price and labor cost per customer.

Standard errors are clustered by network. All variables are logged.

First (last) two columns assume scale effects could be realized in 2003 (2007).

Standard errors in parentheses.

The other coefficients all have the expected signs: In column (2), increasing the number of customers by 1 percent leads to a 0.09 percent decrease in the labor cost. This effect appears relatively low, but is in line with previous studies indicating that scale economies in electricity distribution are in fact modest. As expected, economies of network density is larger, and an increase in the meter of transmission line per customer by 1 percent leads to an increase in the price of 0.17 percent, almost six times as much as the corresponding coefficient on the number of customers. The corresponding scale- and density effects on the price are smaller than the effects on the labor cost, but still statistically significant. For both outcome variables, the effect of increasing the number of transformer stations per customer is positive, as expected, but statistically insignificant. 


\section{Conclusion}

Using a synthetic control method, I examine the effects of privatization in the Swedish electricity distribution sector. Specifically, I examine the effects of private acquisitions of municipality owned distribution networks, that were conducted around the turn of the century. In comparison to their synthetic counterparts, I find that the acquired networks increased labor efficiency by about 18 percent, while no effect is found on the prices. Thus, the evidence suggests substantial efficiency gains but that these are not fed through to consumer prices.

Since each acquisition involved several bordering networks that were separately operated by the municipalities prior to the acquisitions, I examine to what extent the efficiency gains are likely to be driven by increased economies of scale. Results suggest that the entire efficiency gain can be explained by increased economies of scale, questioning the causal effect of privatization per se. However, since the final size of the privatized networks are substantially larger than any of the municipality owned networks in the control group, the identification of this test relies on the possibility to extrapolate outside the data in the control group. Therefore, this result should be interpreted with care.

A topic that could be of interest for future studies concerns the endogeneity of the acquisition decisions, i.e., a selection-into-treatment problem. For example, private firms may opt to acquire networks with the largest potentials for efficiency increases. This could be both with respect to the internal management of the network, or that acquirers look for combinations of networks where the potential for synergy effects are considerable. In some respect, one of the virtues of privatization may be the ability to spot such networks, which relates to the more general discussion on how selection problems should be treated in the literature on privatization of network industries in general.

Just as the concept of private ownership deserves a more nuanced review than what is offered by the present study, so does public ownership. Within the context of labor efficiency, it may for example be that publicly owned firms prefer to offer relatively higher wages and other benefits than private firms ceteris paribus, in which case it is more appropriate to interpret variations in the labor cost as also reflecting how revenues are distributed between workers and owners. 
A shortcoming of the present study is that data on the quality of service (measured by the number and length of outages) has not been able to obtain for the whole sample. As results from previous studies indicate that publicly owned distribution networks achieve a higher quality of service than privately owned networks (see e.g. Kwoka, 2005), this would be a useful outcome variable to examine in future research.

Finally, there may have been other motives for the acquisitions than profiting on distribution per se. Since both Fortum and E.ON control a fair amount of generation facilities in Sweden, they may have incentives to give a disproportionately high priority to the maintenance of distribution lines in connection to their own generation facilities, or in other ways influence the physical constitution of the network to suit their specific needs. They may also use private information about bottlenecks in transmission or power line failures to predict price formation in the wholesale market, creating a strategic advantage compared to other firms. It could therefore be of interest to look into dimensions of market power that considers the strategic aspects of controlling both generation and distribution within the same area, as opposed to examining the behavior in each market separately. 


\section{References}

Abadie, Alberto, Alexis Diamond, and Jens Hainmueller, "Synthetic Control Methods for Comparative Case Studies: Estimating the Effect of California Tobacco Control Program," Journal of the American Statistical Association, 2010, 105 (490), 493-505.

Averch, Harvey and Leland L. Johnson, "Behavior of the Firm Under Regulatory Constraint," The American Economic Review, 1962, 52 (5), 1052-1069.

Balakrishnan, Karthik, Daniel A. Cohen, Xavier Giroud, Kose John, Christo Karuna, April Klein, Thomas Lys, and Raj Mashruwala, "Product Market Competition and Financial Accounting Misreporting," Working Paper, 2012.

Borghi, Elisa, Chiara Del Bo, and Massimo Florio, "Institutions and Firms' Productivity: Evidence from Electricity Distribution in the EU," Oxford Bulletin of Economics and Statistics, 2016, 78 (2), 170-196.

Dalarna's newspaper, "Municipalities wants to buy back the electricity network," http://www.dt.se/dalarna/mora/mora-beredd-kopa-tillbaka-salda-elnatet (accessed April 21, 2016), 2014.

Energy Markets Inspectorate, “Ägarstrukturen på elmarknaden," Report EI R2012:21, Energy Market Inspectorate 2006.

_ , "Utvecklingen av elnätsavgifter 2009-2010," Report PM 2010:03, Energy Market Inspectorate 2011.

_ , "Bedömning av elnätsföretagens nätavgifter nätavgifter 2011," Report Ei R2012:13, Energy Market Inspectorate 2012.

Estache, Antonio and Martín A. Rossi, "Do regulation and ownership drive the efficiency of electricity distribution? Evidence from Latin America," Economics Letters, $2005,86(2), 253-257$.

Heden, H, Energimarkandsinspektionen - en sekellång historia, Energimarkandsinspektionen, ISBN 978-91-977417-1-2, 2012. 
Hjalmarsson, Lennart and Ann Veiderpass, "Efficiency and Ownership in Swedish Electricity Retail Distribution," The Journal of Productivity Analysis, 1992, 3, 7-23.

Jamasb, Tooraj and Magnus Söderberg, "The Effects of Average Norm Model Regulation: The Case of Electricity Distribution in Sweden," Review of Industrial Organization, May 2010, 36 (3), 249-269.

_ and Michael Pollitt, "Reference models and incentive regulation of electricity distribution networks: An evaluation of Sweden's Network Performance Assessment Model (NPAM)," Energy Policy, May 2008, 36 (5), 1788-1801.

Kumbhakar, Subal C. and Lennart Hjalmarsson, "Relative performance of public and private ownership under yardstick competition: electricity retail distribution," European Economic Review, January 1998, 42 (1), 97-122.

Kwoka, John E., "The Comparative Advantage of Public Ownership: Evidence from U.S. Electric Utilities," The Canadian Journal of Economics / Revue canadienne d'Economique, 2005, 38 (2), 622-640.

Laffont, Jean-Jacques and Jean Tirole, A Theory of Incentives in Procurement and Regulation, 1 ed., Vol. 1, The MIT Press, 1993.

Meyer, Roland, "Vertical Economies and the Costs of Separating Electricity Supply: A Review of Theoretical and Empirical Literature," Bremen Energy Working Papers 0006, Bremen Energy Research April 2011.

Muren, Astri, "Exploatering eller reglering av naturliga monopol? Exemplet fjärrvärme," Report 2011:2, Expertgruppen för miljöstudier 2011.

Niskanen, William A., "The Peculiar Economics of Bureaucracy," The American Economic Review, 1968, 58 (2), 293-305.

NordReg, "Economic regulation of electricity grids in Nordic countries," Nordic Energy Regulators, report nr.7, 20112011.

OECD, "Germany - Regulatory Reform in Electricity, Gas, and Pharmacies," Country Studies 2004. 
SABO, "Large price increases in networks owned by E.ON, Fortum and Vattenfall," http://www .sabo.se/aktuellt/nyheter_s/2011/mar/Sidor/St\%C3\%B6rst-pris\% C3\%B6kningar-i-eln\%C3\%A4t-\%C3\%A4gda-av-EON-Fortum-och-Vattenfall aspx (accessed April 21, 2016), 2011.

Salvanes, Kjell G and Sigve Tjøtta, "Productivity differences in multiple output industries: an empirical application to electricity distribution," Journal of Productivity Analysis, 1994, 5 (1), 23-43.

Shleifer, Andrei, "A Theory of Yardstick Competition," RAND Journal of Economics, Autumn 1985, 16 (3), 319-327.

Söderberg, M., "The Role of Model Specification in Finding The Influence of Ownership and Regulatory Regime on Utility Cost: The Case of Swedish Electricity Distribution," Contemporary Economic Policy, 2011, 29 (2), 178-190.

Supreme Administrative Court, "Case 6667-6669-14," http://www. hogstaforvaltningsdomstolen.se/Domstolar/regeringsratten/Avg\%C3\% B6randen/2015/November/6667-6669-14.pdf (accessed April 21, 2016), 2015.

SvD, "Fortum säljer sitt svenska elnät," http://www.svd.se/ fortum-saljer-sitt-svenska-elnat (accessed April 21, 2016), 2015.

SVT, "Borås Elnät utreds av Högsta förvaltningsdomstolen," http://www.svt.se/ nyheter/lokalt/vast/boras-elnat-utreds-av-hogsta-forvaltningsdomstolen (accessed April 21, 2016), 2015.

Swedish Competition Authority, "Consultation response to the NPAM framework," http://www.konkurrensverket.se/Beslut/03-0538.htm (accessed April 21, 2016), 2003. 


\section{Appendix A}

Figure A1: Schematic diagram of the physical supply chain

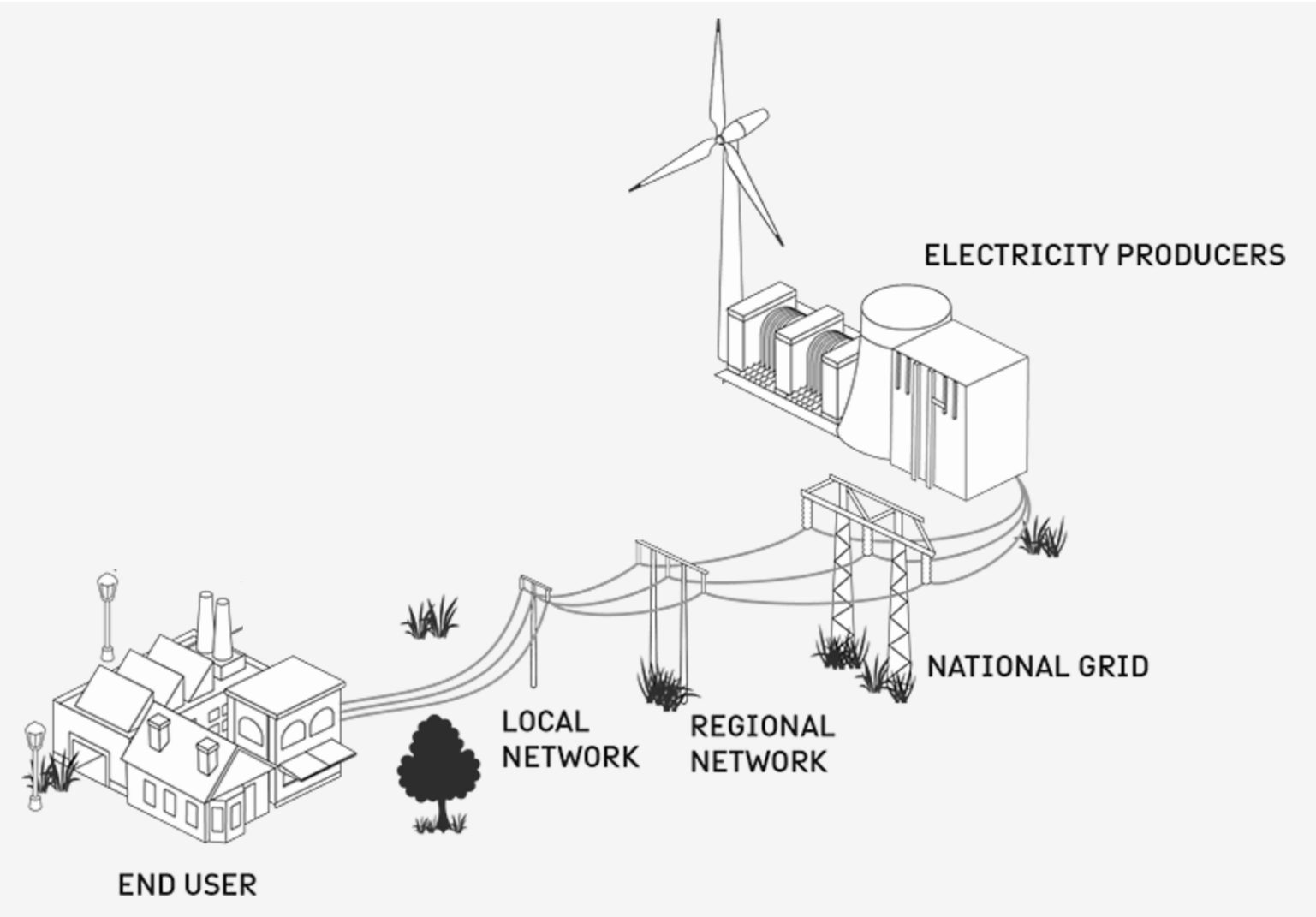

Note: This figure depicts a schematic diagram of the physical route of electricity. The "local network" is equivalent to the distribution network. Source: Svenska Kraftnät. 
Figure A2: Staff expenditures and Other external costs in networks acquired by Fortum

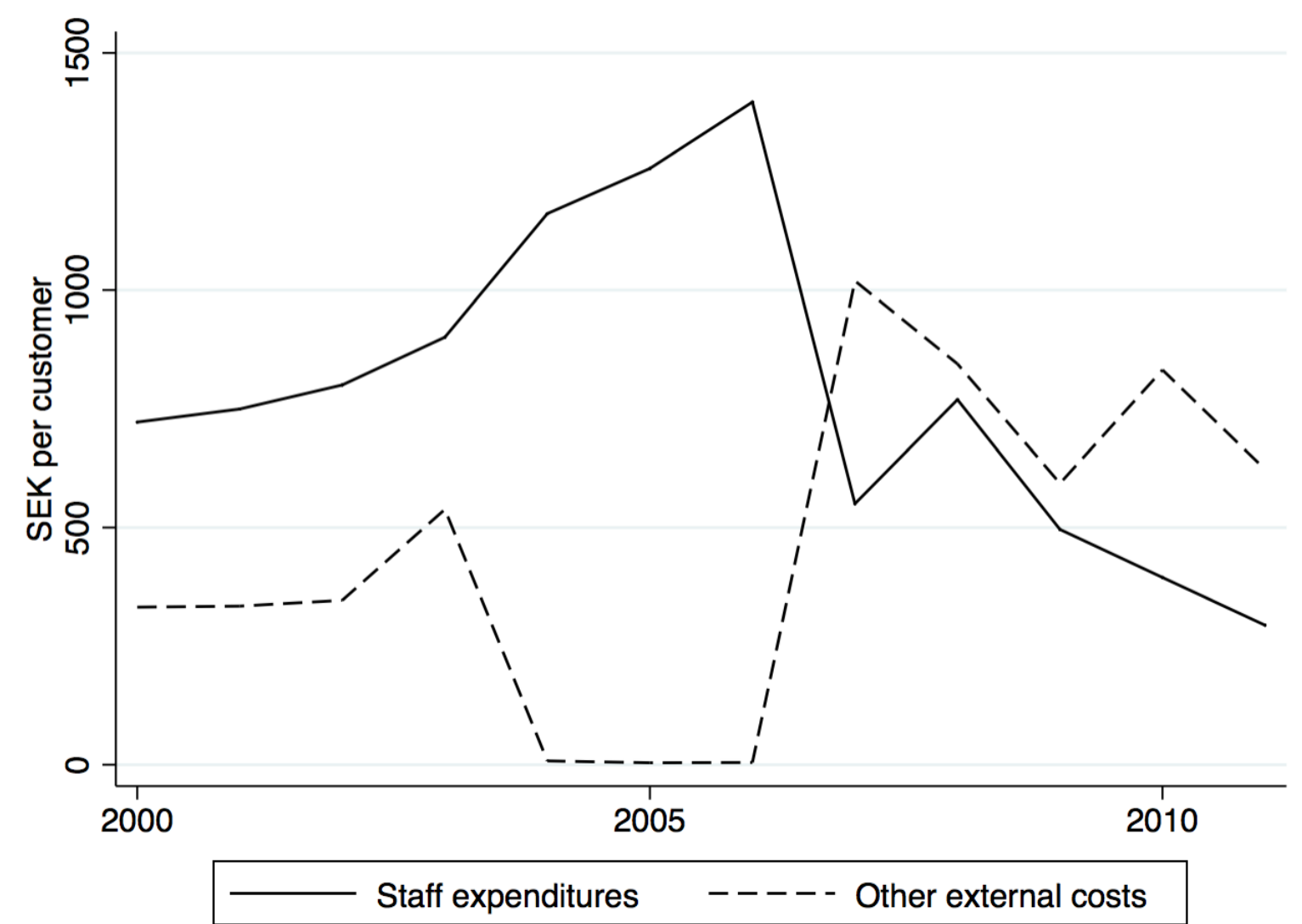

Note: This figure depicts the mean accounted labor cost per customer in the networks acquired by Fortum, disaggregated into Staff expenditures and Other external costs. 
Figure A3: Trends in price and labor cost including networks owned by economic associations
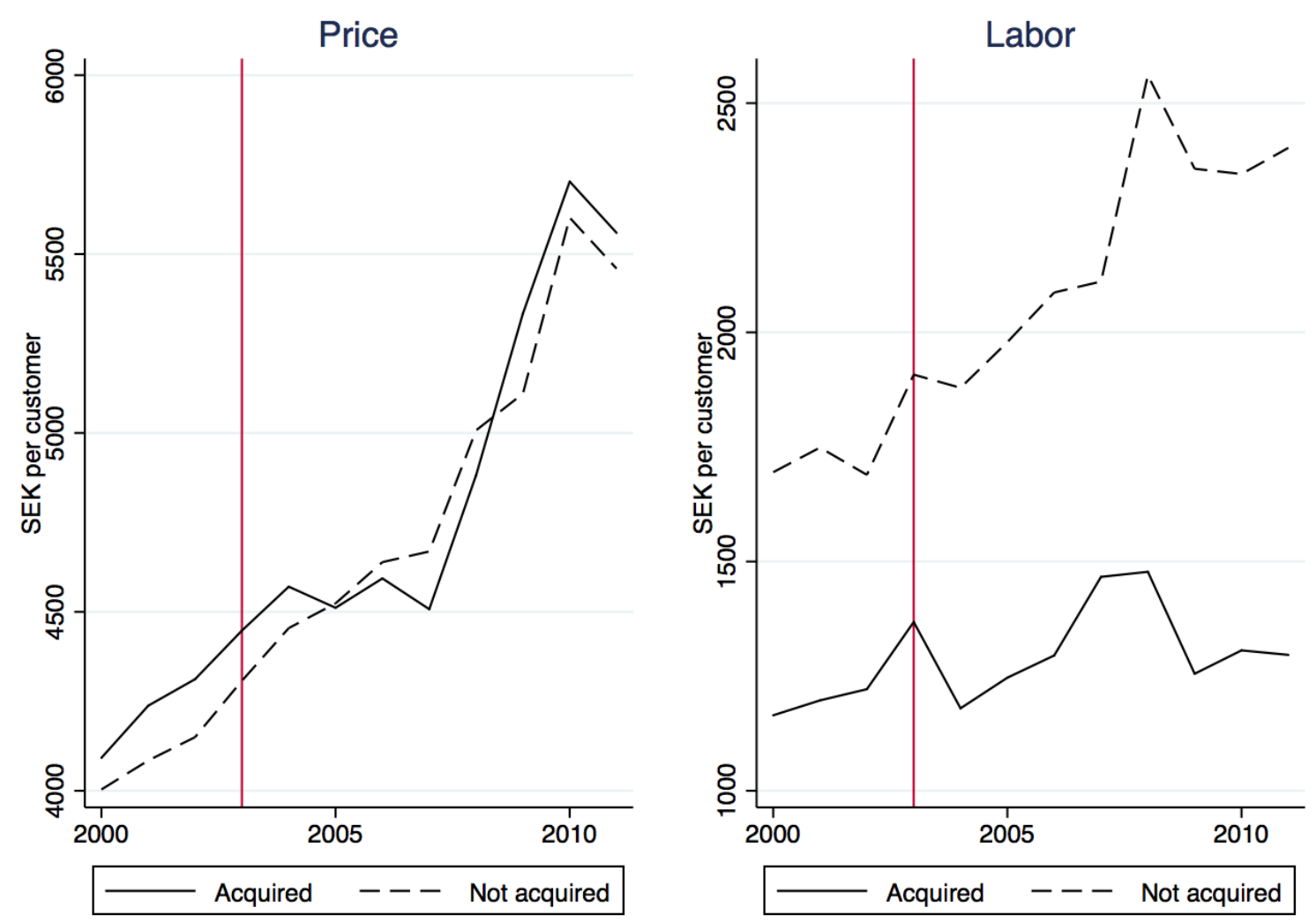

Note: The dashed lines depict the mean price and labor cost per customer for municipality owned networks that were never acquired, including networks owned by economic associations. The solid lines depict the same variables for networks that were acquired by Fortum or E.ON. The vertical line is in 2003. 
Figure A4: Density functions of labor cost and price
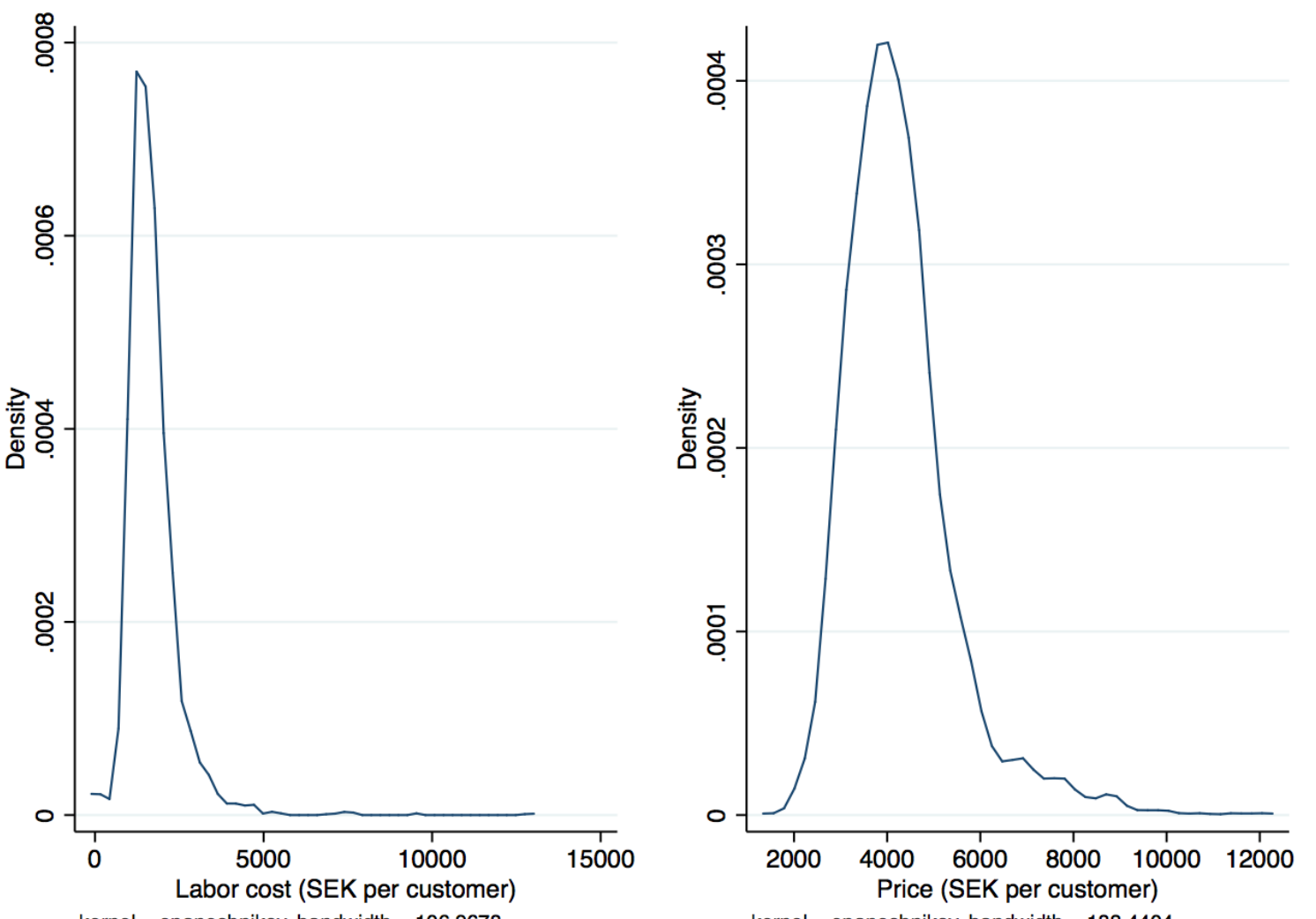

Note: This figure depicts density functions of the outcome variables during the whole sample period for all networks. 
Figure A5: Trajectory of placebo effects
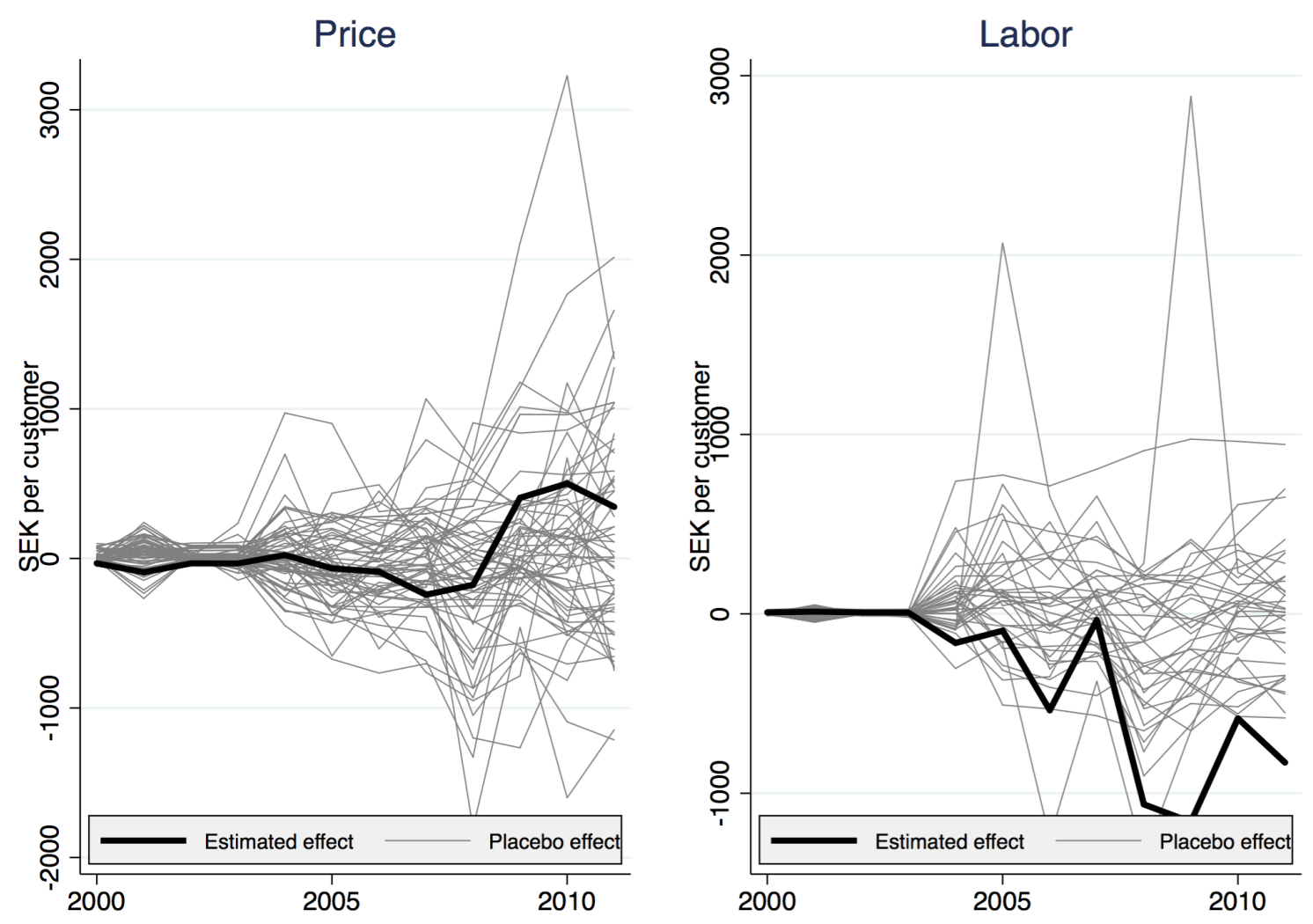

Note: Trajectory of outcome gaps between real and synthetic networks for each network in the sample. Networks with a mean squared prediction error more than twice as large as the acquired network are excluded. 
Figure A6: Trajectory of placebo effects (full sample)
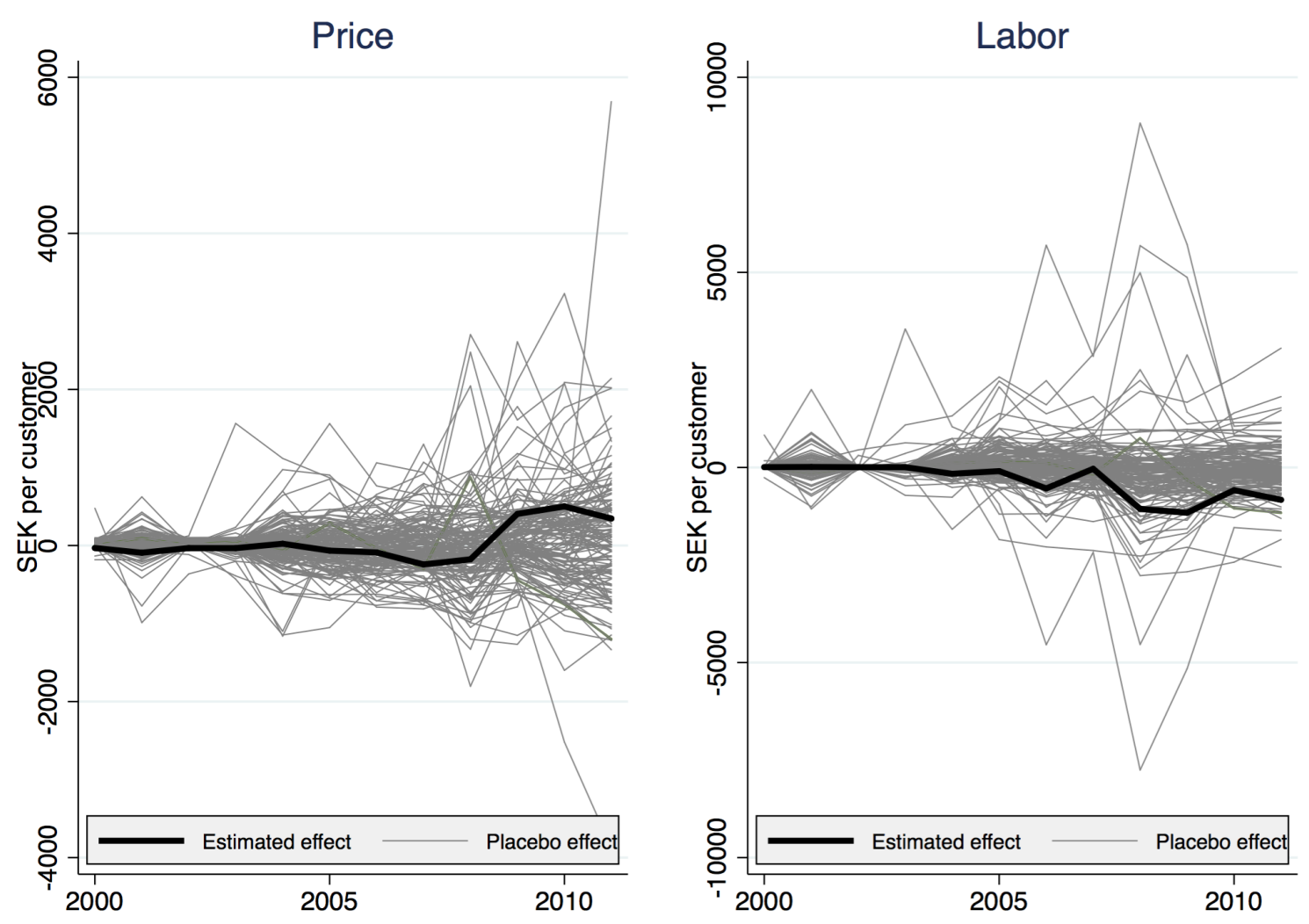

Note: Trajectory of outcome gaps between real and synthetic networks for each network in the sample. All potential control networks have been included. 